\title{
Comparison Study of Uptake of Colorectal Cancer Testing between Ethnic Minorities and the General Population in Hong Kong
}

\author{
Kai-Chow Choi, Winnie Kwok-Wei So*, Joanne Man-Ting Chen, Grace Chieh \\ Lau, Paul Chi-Wai Lee, Carmen Wing-Han Chan
}

\begin{abstract}
Background: Colorectal cancer (CRC) is one of the most common cancers. This study aimed to compare the uptake of CRC testing in the general public and in ethnic minorities in Hong Kong. Materials and Methods: This cross-sectional survey covered 2,327 South Asian and Chinese adults aged over 50, recruited from two separate studies. A structured questionnaires were administered by research staff over the telephone or in faceto-face interviews. Results: The uptake rate of CRC testing among South Asians was significantly lower than that of the general population in Hong Kong. Factors associated with the uptake rate were health professional's recommendation, perception of regular visits to doctor, use of complementary therapy, ethnicity, perceived susceptibility to cancer, presence of chronic illness, and education level. In addition, a significant interaction $(\mathbf{p}<0.05)$ between ethnicity and health professionals' recommendations was found, after adjustment for the main independent factors identified. Conclusions: Older people with lower educational attainment, without chronic illness and those have lower perceived susceptibility to cancer may be targeted for CRC testing promotion in the society. In addition, health professionals can play a highly influential role in promoting such testing, particularly among ethnic minorities.
\end{abstract}

Keywords: Colorectal cancer - cancer testing - ethnic minorities- Hong Kong

Asian Pac J Cancer Prev, 16 (17), 7713-7720

\section{Introduction}

Colorectal cancer (CRC) is the third most common cancer worldwide (International Agency for Research on Cancer [IARC], 2015). There were around 1.4 million newly diagnosed cases in 2012 (IARC, 2015). Overall, $80 \%$ of new cases are in the developed countries, $94 \%$ of deaths occur in individuals aged 50 or more (American Cancer Society [ACS], 2014; World Health Organization [WHO], 2014). Since people with early-stage CRC are often asymptomatic, therefore, screening is crucial for early detection of CRC which can greatly improve the survival rates particularly for older people (Walsh and Terdiman, 2003; WHO, 2015). In fact, various organisations have recommended that people of 50 or more have regular CRC tests (U.S. Preventive Services Task Force [USPSTF], 2008; The Royal Australian College of General Practitioners [RACGP], 2012). Despite continual efforts in health promotion by governments and healthrelated organisations, the uptake rate of CRC screening still remains low, particularly in those countries without a national screening programme for the disease (Etzioni et al., 2004; Palmer et al., 2011).

A number of studies have reported that CRC screening rates among ethnic minorities (EM) are lower than in the general public (Fernandez et al., 2008; Deutekom et al., 2009). EM people perceive inequalities in access to preventive health services, including cancer screening (von Wagner et al., 2011). Language barriers, insurance coverage, perceived discrimination and financial issues are common major factors contributing to the disparity (Austin et al., 2009; Gwede et al., 2011). Reducing the gap in access to preventive health services is an important priority.

An investigation into the CRC screening behaviour of both the general public and ethnic minority in a country without a national screening programme would provide important information and insights to improve the screening uptake and reduce the gap between racial groups. In Hong Kong, there is currently no territory-wide cancer screening programme, and the uptake rate of CRC testing is still low (ranging from 11 to $25 \%$ ) (Wong et al., 2006; So et al., 2012a; So et al., 2012b), despite the Department of Health's recommendation that people aged between 50 and 75 and at average risk should discuss the matter with a doctor and consider undergoing screening for CRC via one of the following methods: faecal occult blood test (FOBT) every one or two years, flexible 
sigmoidoscopy (FS) every five years or colonoscopy every ten years (Cancer Expert Working Group on Cancer Prevention and Screening \& Department of Health [DOH], 2014; Sung et al., 2008). According to the 2011 population census, about $94 \%$ of the overall Hong Kong population are Chinese and the remainder, over 450,000, are ethnic minorities (Census and Statistics Department [CSD], 2012a). The majority of these EM people are South Asians, mainly Indian, Pakistani or Nepalese (Census and Statistics Department [CSD], 2012b).

In this study, we aim to compare the uptake of CRC testing among the general public and EM people in Hong Kong. We also identify factors, including ethnicity, associated with CRC testing uptake to guide the selection of subjects for intervention. Furthermore, we examine whether the effects of these factors on the uptake rate vary with ethnicity.

\section{Materials and Methods}

\section{Study populations}

From the general public, 2,004 participants were identified from a population-based cross-sectional telephone survey that had examined cancer screening behaviour among Hong Kong Chinese communitydwelling people aged 50 or more (So et al., 2012b). A further $323 \mathrm{EM}$ participants were included from another study that had explored the experience of cancer screening from the perspective of ethnic minorities in Hong Kong, conducted during 2012 and 2013 (So et al., 2013).

Recruitment inclusion criteria for the general public group were: Hong Kong Chinese residents who were (1) aged 50 or older, (2) from domestic households and (3) able to communicate in Cantonese. The parallel inclusion criteria for the EM group were: (1) aged 50 or older and (2) of Indian, Nepalese or Pakistani ethnicity. The general public participants were recruited via an anonymous random-digit telephone dialling survey. EM participants were recruited from more than 20 community centres providing support for South Asians in Hong Kong. All eligible participants were briefed about the study aims and procedures, and verbal or written consent was sought from all the Chinese and South Asian participants. Ethical approval for both studies was obtained from the Survey and Behavioural Research Ethics Committee of the Chinese University of Hong Kong prior to data collection.

\section{Questionnaires}

The questionnaires for cancer screening behavior, forming part of both studies, were very similar. Only the data on relevant common items from both studies were extracted for the present comparison study, in six sections: perceived health status, use of complementary medicine, use of screening tests, perceived susceptibility to cancer, family history and demographic detail. Participants' health status was established using five items in Section 1. These included whether they had any chronic diseases or had been diagnosed with cancer in the past and whether they took regular preventive health measures, such as visiting the dentist. Section 2 is an one-item section concerning participant's use of complementary therapy, a term that covers a range of common therapies which have been included to contribute to an understanding of any association between the use of this type of therapy and cancer-screening behaviour. In Section 3, participants were required to state whether they had attended CRC screening and, if so, the frequency, location, source of finance (such as health insurance coverage) and the main reason for either attending or not attending. Importantly, they were asked to identify who initiated the screening process and also to say whether a test had ever produced an abnormal result, and to describe any follow-up action required. This section was modified from the cancer screening section of the 2005 cancer module of the National Health Interview Survey for Chinese and South Asians participants (Centres for Disease Control and Prevention [CDC], 2006). Section 4 consists of two items assessing participants' perceptions of their susceptibility to cancer. Four items covering any history of cancer in the participant's biological father, mother and full siblings appeared in Section 5. Demographic data associated with the use of healthcare services are obtained in Section 6 (Etzioni et al., 2004).

The Hindi, Urdu and Nepali versions of the questionnaire are produced for Pakistani, Indian and Nepalese participants respectively, using a backtranslation procedure. A member of the research staff fluent in English and Hindi first translated the English version into Hindi, and another translator also fluent in both languages translated it back into English. The researchers then compared the original source with the back-translated version to ensure content and semantic equivalence. The same procedure is adopted to produce Urdu and Nepali versions of the English survey.

\section{Statistical analysis}

All data were summarised and presented using appropriate descriptive statistics. Characteristics of general public and EM participants were compared using chi-square or independent t-tests. The uptake of any CRC screening tests in the past, including occult blood test and colonoscopy, was set as the outcome of the comparison study. Backward stepwise multivariable logistic regression was used to identify factors associated with screening test uptake by the participants. Further multivariable logistic regressions were performed to examine the interaction effect between each of the above significant factors and ethnicity after adjusting for the main effects of the factors identified. All statistical analyses were performed using IBM SPSS 22 (IBM Corp. Armonk NY). All statistical tests involved were two-sided and the level of significance was set at 0.05 .

\section{Results}

A total of 2,004 general public (GP) and 323 ethnic minority (EM) participants were included in the study. The characteristics of the two groups appear in Table 1.

\section{Socio-demographic characteristics}

The mean ages of the GP and EM groups were $63.8 \pm 10.4$ and $61.1 \pm 7.8$, respectively. The distribution 
of sex and educational attainment in the two groups were similar. However, compared with the GP group, a significantly higher proportion of the EM group were employed, married or cohabiting, and has a lower monthly household income (Table 1).

\section{Health status and use of complementary therapy}

A significantly smaller proportion of the EM group had chronic illness or a family history of cancer, was smokers or had used complementary therapy than the GP group (Table 1).

Health-related perceptions
A Colorectal Cancer Testing Comparison Study in Hong Kong

Participants in the EM group were less likely to perceive their health status as fair or poor but more likely to perceive a higher susceptibility to cancer than the GP group. In general, more GP than EM participants believed that exercising, maintaining a healthy diet and visiting a doctor regularly were good for the health (Table 1).

Use of CRC screening test, and reasons for having or not having a test

Among the 25\% GP participants and 10\% EM participants had ever had any CRC test $(p<0.001)$, and $7 \%$ and $3 \%$ of them had received a health professional's recommendation for a CRC test respectively $(p=0.005)$

Table 1. Characteristics of the Respondents

\begin{tabular}{|c|c|c|c|}
\hline & General public $(\mathrm{n}=2004)$ & Ethnic minority $(\mathrm{n}=323)$ & p-value \\
\hline \multicolumn{4}{|l|}{ Socio-demographic characteristics } \\
\hline Age (years) [mean (standard deviation)] & $63.8(10.4)$ & $61.1(7.8)$ & $<0.001$ \\
\hline \multicolumn{4}{|l|}{$\operatorname{Sex}$} \\
\hline Female & $1002(50.0 \%)$ & $161(49.8 \%)$ & \multirow[t]{2}{*}{0.959} \\
\hline Male & $1002(50.0 \%)$ & $162(50.2 \%)$ & \\
\hline \multicolumn{4}{|l|}{ Education level } \\
\hline Primary or below & $933(46.7 \%)$ & $145(45.0 \%)$ & \multirow[t]{3}{*}{0.541} \\
\hline Secondary & $840(42.0 \%)$ & $134(41.6 \%)$ & \\
\hline Tertiary or above & $225(11.3 \%)$ & $43(13.4 \%)$ & \\
\hline \multicolumn{4}{|l|}{ Full / part - time working } \\
\hline No & $1525(76.3 \%)$ & $186(57.6 \%)$ & \multirow[t]{2}{*}{$<0.001$} \\
\hline Yes & $474(23.7 \%)$ & $137(42.4 \%)$ & \\
\hline \multicolumn{4}{|c|}{ Monthly household income $(\mathrm{HK} \$)$ \# [US\$1 $\approx \mathrm{HK} \$ 7.8]$} \\
\hline$<10,000$ & $616(30.7 \%)$ & $114(35.3 \%)$ & \multirow[t]{4}{*}{$<0.001$} \\
\hline $10,000-19,999$ & $267(13.3 \%)$ & $100(31.0 \%)$ & \\
\hline 20,000 & $402(20.1 \%)$ & $69(21.4 \%)$ & \\
\hline Don't know / decline to disclose & $719(35.9 \%)$ & $40(12.4 \%)$ & \\
\hline \multicolumn{4}{|l|}{ Marital status } \\
\hline Single / divorced / widowed & $489(24.6 \%)$ & $41(12.7 \%)$ & \multirow[t]{2}{*}{$<0.001$} \\
\hline Married / cohabited & $1497(75.4 \%)$ & $282(87.3 \%)$ & \\
\hline \multicolumn{4}{|l|}{ Family history of cancer } \\
\hline No / don’t know & $1566(78.1 \%)$ & $289(89.5 \%)$ & \multirow[t]{2}{*}{$<0.001$} \\
\hline Yes & $438(21.9 \%)$ & $34(10.5 \%)$ & \\
\hline \multicolumn{4}{|l|}{ Health status } \\
\hline \multicolumn{4}{|l|}{ Chronic illness } \\
\hline Any confirmed chronic illness & $896(44.7 \%)$ & $100(31.0 \%)$ & $<0.001$ \\
\hline \multicolumn{4}{|l|}{ Smoking status } \\
\hline Never smoker & $1534(76.5 \%)$ & $278(86.1 \%)$ & \multirow[t]{3}{*}{$<0.001$} \\
\hline Ex-smoker & $244(12.2 \%)$ & $21(6.5 \%)$ & \\
\hline Current smoker & $226(11.3 \%)$ & $24(7.4 \%)$ & \\
\hline \multicolumn{4}{|l|}{ Utilisation of complementary therapy } \\
\hline \multicolumn{4}{|l|}{ Use of complementary therapy } \\
\hline No & $1009(50.3 \%)$ & $210(65.2 \%)$ & \multirow[t]{2}{*}{$<0.001$} \\
\hline Yes & $995(49.7 \%)$ & $112(34.8 \%)$ & \\
\hline \multicolumn{4}{|l|}{ Health related perceptions } \\
\hline \multicolumn{4}{|l|}{ Perceived health status } \\
\hline Excellent / very good / good & $869(43.4 \%)$ & $200(61.9 \%)$ & \multirow[t]{2}{*}{$<0.001$} \\
\hline Fair / poor & $1135(56.6 \%)$ & $123(38.1 \%)$ & \\
\hline \multicolumn{4}{|c|}{ Perceived that following practices are good for health } \\
\hline Doing exercise & $1525(76.1 \%)$ & $226(70.0 \%)$ & 0.018 \\
\hline Maintaining a healthy diet & $1419(70.8 \%)$ & $226(70.0 \%)$ & 0.758 \\
\hline Visiting a doctor regularly & $912(45.5 \%)$ & $113(35.0 \%)$ & $<0.001$ \\
\hline Perceived susceptibility to cancer (range & $t$ at all likely to $10=$ extren & ly likely) & \\
\hline$\leq 5$ & $1319(65.8 \%)$ & $273(84.5 \%)$ & $<0.001$ \\
\hline$>5$ & $139(6.9 \%)$ & $41(12.7 \%)$ & \\
\hline Unsure & $546(27.2 \%)$ & $9(2.8 \%)$ & \\
\hline
\end{tabular}

Data are presented as frequency (\%), except age where mean and standard deviation are presented 
Kai-Chow Choi et al

(Table 2). Among those who had ever had a CRC screening test, the EM group were more likely than the GP group to have undergone their most recent test in the past year $(50 \%$ vs $31 \%, p=0.004)$ (Table 2$)$. There was no significant difference between the two groups in the number of tests undergone in the past six years and the proportion of abnormal test results (Table 2). The most important responses about not having a test in the EM group were 'No reason / never thought about it' (36\%), and 'Not necessary' (67\%) for the GP group. On the other hand, the main reason for having the most recent test was 'Part of a routine examination' (56\%) and 'Body check' (50\%) for the EM and GP groups, respectively (Table 3).

Factors associated with the uptake of CRC screening tests Based on backward multivariable logistic regressions, ethnicity, educational level, presence of chronic illness, use of complementary therapy, perception that visiting a doctor

Table 2. Use of Colorectal Cancer Screening Test

\begin{tabular}{|c|c|c|c|}
\hline Among all respondents & General public $(\mathrm{n}=2004)$ & Ethnic minorities $(n=323)$ & p-value \\
\hline \multicolumn{4}{|c|}{ Any health professional recommended a CRC screening test } \\
\hline No & $1865(93.1 \%)$ & $314(97.2 \%)$ & 0.005 \\
\hline Yes & $139(6.9 \%)$ & $9(2.8 \%)$ & \\
\hline \multicolumn{4}{|l|}{ Ever had the CRC test } \\
\hline No & $1513(75.5 \%)$ & $291(90.1 \%)$ & $<0.001$ \\
\hline Yes & $491(24.5 \%)$ & $32(9.9 \%)$ & \\
\hline Among those who ever had any CRC test & General public $(n=491)$ & Ethnic minorities $(n=32)$ & \\
\hline \multicolumn{4}{|c|}{ Number of the test undergone in the past 6 years } \\
\hline 0 & $80(16.3 \%)$ & $3(9.4 \%)$ & 0.271 \\
\hline 1 & $164(33.4 \%)$ & $8(25.0 \%)$ & \\
\hline $2-3$ & $139(28.3 \%)$ & $13(40.6 \%)$ & \\
\hline$>3$ & $96(19.6 \%)$ & $6(18.8 \%)$ & \\
\hline Unsure & $12(2.4 \%)$ & $2(6.3 \%)$ & \\
\hline \multicolumn{4}{|l|}{ Time since the most recent test } \\
\hline$\leq 1$ year & $154(31.4 \%)$ & $16(50.0 \%)$ & 0.004 \\
\hline$>1-2$ years & $48(9.8 \%)$ & $5(15.6 \%)$ & \\
\hline$>2-3$ years & $38(7.7 \%)$ & $3(9.4 \%)$ & \\
\hline$>3-4$ years & $32(6.5 \%)$ & $3(9.4 \%)$ & \\
\hline$>4-5$ years & $19(3.9 \%)$ & $1(3.1 \%)$ & \\
\hline$>5$ years & $79(16.1 \%)$ & $4(12.5 \%)$ & \\
\hline Unsure & $121(24.6 \%)$ & $0(0.0 \%)$ & \\
\hline \multicolumn{4}{|l|}{ Ever had an abnormal test result } \\
\hline No & $448(91.2 \%)$ & $29(90.6 \%)$ & 0.391 \\
\hline Yes & $39(7.9 \%)$ & $2(6.3 \%)$ & \\
\hline Unsure & $4(0.8 \%)$ & $1(3.1 \%)$ & \\
\hline
\end{tabular}

Data are presented as frequency $(\%)$.

\section{Table 3. Reasons for Having and not Having the CRC Screening test}

The most important reasons for not having the test among those who have not ever had a CRC screening test General public $(\mathrm{n}=1513)$ Ethnic minorities $(\mathrm{n}=291)$

\begin{tabular}{lc}
\hline 1. Not necessary & 1. No reason / never thought about it \\
$1011(66.8 \%)$ & $106(36.4 \%)$ \\
2. Healthy all along & 2. Didn't need it/didn't know I needed this kind of test \\
$177(11.7 \%)$ & $66(22.7 \%)$ \\
3. Doctor did not suggest & 3. Haven't had any problems \\
$85(5.6 \%)$ & $52(17.9 \%)$ \\
4. No reason & 4. Doctor didn't order it/didn't say I needed it \\
$76(5.0 \%)$ & $45(15.5 \%)$ \\
5. Don't know this test available & 5. Don't know \\
$71(4.7 \%)$ & $7(2.4 \%)$ \\
\hline The main reason of the most recent test among those who have ever had a CRC screening test \\
General public (n=491) & Ethnic minorities (n=32) \\
\hline 1. Body checkup & 1. Part of a routine examination \\
$244(49.7 \%)$ & $18(56.2 \%)$ \\
2. Unusual bowel patterns/symptoms\# & 2. Unusual bowel patterns/symptoms\# \\
$135(27.5 \%)$ & $11(34.4 \%)$ \\
3. Doctor suggestion & 3. Doctor's suggestion \\
$65(13.2 \%)$ & $2(6.2 \%)$ \\
\hline
\end{tabular}

Data are presented as frequency (\%); \#unusual bowel patterns / symptoms: bleeding/difficulty in passing stool/discomfort/pain/diarrhea 
Table 4. Multivariable logistic regression analysis of factors associated with the uptake of a CRC screening test

\begin{tabular}{|c|c|c|}
\hline Significant factors & Odds ratio $(95 \% \mathrm{CI})$ & $\mathrm{p}$-value \\
\hline \multicolumn{3}{|l|}{ Ethnicity } \\
\hline General public (ref) & 1 & \\
\hline Ethnic minority & $0.42(0.28-0.62)$ & $<0.001$ \\
\hline \multicolumn{3}{|l|}{ Education level } \\
\hline Primary or below (ref) & 1 & \\
\hline Secondary & $1.17(0.93-1.47)$ & 0.171 \\
\hline Tertiary or above & $1.51(1.09-2.11)$ & 0.014 \\
\hline \multicolumn{3}{|c|}{ Any confirmed chronic illness } \\
\hline No (ref) & 1 & \\
\hline Yes & $1.34(1.08-1.66)$ & 0.009 \\
\hline \multicolumn{3}{|c|}{ Use of complementary therapy } \\
\hline No (ref) & 1 & \\
\hline Yes & $1.60(1.29-1.98)$ & $<0.001$ \\
\hline \multicolumn{3}{|c|}{ Perceived visiting a doctor regularly is good for health } \\
\hline No (ref) & 1 & \\
\hline Yes & $2.10(1.69-2.60)$ & $<0.001$ \\
\hline \multicolumn{3}{|c|}{ Perceived susceptibility to cancer (ranged from $1=$ not at all likely to $10=$ extremely likely) } \\
\hline$\leq 5$ (ref) & 1 & \\
\hline$>5$ & $1.74(1.21-2.51)$ & 0.003 \\
\hline Unsure & $1.16(0.91-1.49)$ & 0.236 \\
\hline \multicolumn{3}{|c|}{ Health professional's recommendation } \\
\hline No (ref) & 1 & \\
\hline Yes & $6.86(4.73-9.95)$ & $<0.001$ \\
\hline
\end{tabular}

Model 2: The factors identified in model 1 with significant interaction with ethnicity after adjusting for the main effects of all the factors identified in model 1

\begin{tabular}{lcr}
\hline Factors with significant interaction with ethnicity & Odds ratio (95\% CI) & p-value \\
\hline Ethnicity * Health professional's recommendation & $17.4(2.0-152.7)$ & 0.010 \\
\hline Ethnic minority \& Having a Health professional's recommendation vs others & 170 \\
\hline ref: reference group of the categorical variable & &
\end{tabular}

regularly was good for the health, perceived susceptibility to cancer and health professionals' recommendations were found to be independently associated with the uptake of screening tests (Table 4, Model 1). The EM group was less likely to have ever had a test than the GP group (adjusted odds ratio, $\mathrm{AOR}=0.42,95 \%$ confidence interval, $\mathrm{CI}$ : $0.28-0.62, p<0.001)$. Participants with lower educational attainment, those who had only primary or lower education were less likely to take a test, AOR=0.66 (95\% CI: 0.48 $0.92), p=0.014$ when compared with those with tertiary or higher level. Participants without any chronic illness, who did not use complementary therapy, who did not believe visiting a doctor regularly was good for the health and those without a health professional's recommendation were all associated with decreased odds of having a CRC test (AOR ranged from 0.15 to 0.75 , all $p<0.05$, Table 4 , Model 1). Moreover, those who had a lower perceived susceptibility to cancer were less likely to have a test than those with a higher perceived susceptibility, AOR $=0.58$ (95\% CI: $0.40-0.83), p=0.003$.

Also, the interaction between ethnicity and the factors identified above were assessed using multivariable logistic regressions. Only health professionals' recommendations were found to interact significantly with ethnicity in association with testing uptake, after adjusting for the main effects of the factors identified (Table 4, Model 2). EM people without a health professional's recommendation would have further decreased odds of test uptake, AOR of the interaction term between ethnicity and health professional's recommendation $=0.06(95 \% \mathrm{CI}: 0.01$ $0.50), p=0.010$.

\section{Discussion}

To our knowledge, this is the first study to examine the difference in the uptake rate of CRC testing between GP and EM people in a mainstream Chinese society. Both GP and EM uptake rates were low, with the EM rate significantly lower than the GP (10\% vs $25 \%)$. In this society, moreover, lower educational attainment, absence of chronic illness, no complementary therapy, not believing regular visits to a doctor were good for the health, lower perceived susceptibility to cancer and no health professional's recommendation were all factors independently associated with decreased odds of having a CRC test. There was no significant difference between GP and EM groups in the effects of the above factors on the uptake of testing, except that the effect of a health professional's recommendation for EM was significantly higher than for GP. This indicates that health professionals can play a crucial role in promoting screening tests, particularly to EM people.

In fact, the present result is consistent with previous studies in finding that a health professional's 
recommendation is an important factor contributing to the use of CRC screening (Etzioni et al., 2004; Fernandez et al., 2008; Griffith, 2009; Palmer et al., 2011). The low uptake rate of CRC screening in the study populations can be largely explained by the low rate of health professionals' recommendations for such testing, suggesting that a recommendation from a health professional is the strongest external cue to action. Only $7 \%$ of the GP and 3\% of the EM groups in the current study population received a recommendation from a health professional, much lower figures than the $67-68 \%$ of the ethnic minority group (African-Americans) reported in studies conducted in the US (Griffith, 2009; Palmer et al., 2011).

Also, previous studies have found that barriers to professional recommendation include prior patient refusal of screening, lack of reminder or test tracking systems, and a lack of knowledge of the recommended screening modalities (Sewitch et al., 2006; Guerra et al., 2007). The region-specific guidelines on prevention and screening for early CRC diagnosis have recently been developed by an Asia Pacific Working Group on Colorectal Cancer (Sung et al., 2008), and they should certainly be disseminated among different clinical settings to ensure they are widely used. The low rate of health professionals' recommendations in EM might be attributed to a failure of communication with the EM population. Szczepura (2005) suggests that communication is a challenge for $\mathrm{EM}$ on the way to equitable access to proper healthcare.

More precise insights can be gained by applying the health belief model (HBM). The reasons for not having a CRC screening test reported by EM can be recognised as different constructs in HBM. 'No reason/never thought about it' and 'didn't need it/didn't know I needed this kind of test' were reported as two of the most common reasons not participating in CRC screening for EM group, implying that a lack of awareness and inadequate knowledge of CRC act as barriers to CRC screening in EM (Robb et al., 2008).

First, EM participants may not be aware that the chances of developing CRC increase remarkably after the age of 50 (CSD, 2012a), when they are susceptible to CRC. This is in line with the multivariable logistic regression results, that educational attainment and low perceived susceptibility to cancer are associated with lower uptake rate of CRC screening (Table 4, Model 1). Second, inadequate knowledge of the importance of screening tests might also affect belief in the expected benefits or positive outcomes associated with CRC screening. For example, screening could detect changes in the colon before CRC develops and the disease could then be effectively treated if it can be diagnosed early. Lower level of perceiving the severity of cancer is also suggested. EM people might not be aware of the serious clinical and social consequences of CRC, from death to the impact on family and social life. 'Haven't had any problems' can be considered as a misconception of CRC screening, which may appear to the EM as a treatment option rather than prevention of CRC and an early detection of colorectal changes. It was implicated that when individuals lack knowledge of CRC and early detection measures, the role of healthcare providers becomes more prominent. In other words, when an individual has only a weak personal belief in implementing health behaviour, the presence of external cues to action becomes the strongest motivation for specific health-seeking behaviour.

The lack of knowledge among EMs on the availability of CRC screening and the fewer recommendations for CRC tests made by healthcare professionals suggest a certain inequity. The Asia Pacific consensus guidelines state that screening should be started at the age of 50 (Sung et al., 2008), but the EM group received significantly fewer recommendations than GP who are aged over 50 . This could be due to the access barriers to healthcare professionals in the EM environment. Language difficulties are likely to be a prominent barrier for EM to access healthcare resources, since Cantonese is the main communication channel in public healthcare settings in Hong Kong, and materials promoting CRC preventive services are rarely prepared in Urdu or Nepali.

According to the results of the study, the following recommendations targeting EM and service providers are made to encourage the uptake of CRC screening in EM. First, in respect of individual beliefs and attitudes, awareness of CRC and preventive services should be promoted to the EM.Linguistically and culturally relevant printed health materials or education programmes should be developed to enhance EMs' knowledge of CRC. Second, interventions at the community level should be undertaken by healthcare providers Policy-makers should be encouraged to work collaboratively with the university and community organization to develop an ethnic-specific strategy to increase the rate, in view of the EM disparity. The region-specific guidelines on prevention and screening for early CRC diagnosis that have recently been developed by an Asia Pacific Working Group on Colorectal Cancer (Sung et al., 2008) should be distributed among different clinical settings to ensure they are widely used.

In addition, the promotion of primary healthcare and the provision of training for health professionals are essential measures to promote the uptake of CRC testing. Primary healthcare focuses on prevention and health promotion, including access to health services, environment and lifestyle, and emphasizes the full participation of individuals. Local strategies were documented in 2010 (Food and Health Bureau [FHB], 2010), but they should also be spread more widely, to EM. Interventions concerned with medical education and team-building strategic planning exercises for healthcare providers are effective in increasing the referral and completion of CRC (Lane et al., 2008). Also, training for healthcare professionals in communication skills can also improve the screening rate (Naylor et al., 2012).

This study has several limitations, and some caution is needed in interpreting the findings. Although the survey was conducted anonymously, the results may be subjected to self-report, recall and social desirability biases. This was a cross-sectional study, and the factors found to be associated with the uptake of CRC testing could not guarantee any causal relationship. Finally, information on whether participants had ever been diagnosed with 
CRC was not collected in the survey - the uptake rate of a CRC screening in the population might have been over-estimated, although this margin is unlikely to have involved very large number of people.

Older people of lower educational attainment, without chronic illness and with a lower perceived susceptibility to cancer may be targeted for promoting CRC tests in societies without an official screening programme. Our results also support the view that health professionals can play a highly influential role in promoting such screening tests, particularly to ethnic minority people. Efforts should be made to educate the general public about the benefits and importance of CRC screening, as well as increasing their awareness of the disease. An ethnic-specific strategy should be developed to increase the uptake rate of CRC test in view of ethnic differences.

\section{Acknowledgements}

Public Policy Research Funding Scheme, Research Grants Council (Ref. 2190233) and the Chinese University of Hong Kong had funded the two studies. The authors thank Ms Alice Leung, Ms Vivian Wu and all the data collectors for their assistance with data collection and entry. Also, our sincere thanks go to the following organisations who supported the study: United Christian Nethersole Community Health Service, Christian ActionSHINE Centre, HOPE Center, Hong Kong Sheng Kung Hui Lady MacLehose Center, Support Service Centres For Ethnic Minorities, The Neighbourhood Advice-Action Council Tung Chung Integrated Service Centre, The Vine Church, Inner City Minerstries, Mission To New Arrivals Ltd., Securitas Hong Kong, New Home Association, United Nepali Christian Church Hong Kong, The Pakistani Association of Hong Kong, Khalsa Diwan (Sikh Temple) Hong Kong, Pakistan Islamic Welfare Union Incorporated (HK) Ltd., Hindu Temple of Hong Kong, Kowloon Hindu Mandir (Temple), ISKCON Temple Hong Kong, Sathya Sai Baba Center of Hong Kong, Hong Kong Nepalese Federation.

\section{References}

American Cancer Society. 2014. Colorectal cancer facts \& figures 2014-2016 [Online].

Austin KL, Power E, Solarin I, et al (2009). Perceived barriers to flexible sigmoidoscopy screening for colorectal cancer among UK ethnic minority groups: A qualitative study. $J$ Med Screen, 16, 174-9.

Cancer Expert Working Group on Cancer Prevention and Screening \& Department of Health. 2014. Prevention and screening for colorectal cancer [Online].

Census and Statistics Department. 2012a. 2011 population census. Summary results [Online].

Census and Statistics Department. 2012b. 2011 population census. Thematic report: Ethnic minority. [Online].

Centres for Disease Control and Prevention. 2006. 2005 National Health Interview Survey (NHIS): NHIS survey description [Online].

Deutekom M, van Rijn AF, Dekker E, et al (2009). Uptake of faecal occult blood test colorectal cancer screening by different ethnic groups in the Netherlands. Eur J Public
A Colorectal Cancer Testing Comparison Study in Hong Kong

Health, 19, 400-2.

Etzioni DA, Ponce NA, Babey SH, et al (2004). A populationbased study of colorectal cancer test use: results from the 2001 California Health Interview Survey. Cancer, 101, 2523-32.

Fernandez ME, Wippold R, Torres-Vigil I, et al (2008). Colorectal cancer screening among Latinos from U.S. cities along the Texas-Mexico border. Cancer Causes Control, 19, 195-206.

Food and Health Bureau. 2010. Primary care development in Hong Kong: Strategy document [Online].

Griffith KA (2009). Biological, psychological and behavioral, and social variables influencing colorectal cancer screening in African Americans. Nurs Res, 58, 312-20.

Guerra CE, Schwartz JS, Armstrong K, et al (2007). Barriers of and facilitators to physician recommendation of colorectal cancer screening. J Gen Intern Med, 22, 1681-8.

Gwede CK, Jean-Francois E, Quinn GP, et al (2011). Perceptions of colorectal cancer among three ethnic subgroups of US blacks: A qualitative study. J Natl Med Assoc, 103, 669-80.

International Agency for Research on Cancer 2015. World cancer report 2014, Geneva, World Health Organization.

Lane DS, Messina CR, Cavanagh MF, et al (2008). A provider intervention to improve colorectal cancer screening in county health centers. Med Care, 46, 109-16.

Naylor K, Ward J, Polite BN (2012). Interventions to improve care related to colorectal cancer among racial and ethnic minorities: A systematic review. J Gen Intern Med, 27, 1033-46.

Palmer RC, Chhabra D, McKinney S (2011). Colorectal cancer screening adherence in African-American men and women 50 years of age and older living in Maryland. $J$ Community Health, 36, 517-24.

Robb KA, Solarin I, Power E, et al (2008). Attitudes to colorectal cancer screening among ethnic minority groups in the UK. BMC Public Health, 8, 34.

Sewitch MJ, Burtin P, Dawes M, et al (2006). Colorectal cancer screening: Physicians' knowledge of risk assessment and guidelines, practice, and description of barriers and facilitators. Can J Gastroenterol Hepatol, 20, 713-8.

So WK, Chan CW, Choi KC, et al (2013). Perspectives on the use of and service needs of cancer preventive services for ethnic minorities in Hong Kong: A study protocol. $J$ Adv Nurs, 69, 2116-22.

So WK, Choi KC, Chan DN, et al (2012a). Colorectal cancer testing and associated factors among older Chinese adults. Prev Med, 54, 104-5.

So WK, Choi KC, Chan DN, et al (2012b). Colorectal cancer screening behaviour and associated factors among Chinese aged 50 and above in Hong Kong - A population-based survey. Eur J Oncol Nurs, 16, 413-8.

Sung JJ, Lau JY, Young GP, et al (2008). Asia Pacific consensus recommendations for colorectal cancer screening. Gut, 57, $1166-76$.

Szczepura A (2005). Access to health care for ethnic minority populations. Postgrad Med J, 81, 141-7.

The Royal Australian College of General Practitioners. 2012. Guidelines for preventive activities in general practice [Online].

U.S. Preventive Services Task Force. 2008. Colorectal cancer: Screening. Screening recommendation. [Online].

von Wagner C, Baio G, Raine R, et al (2011). Inequalities in participation in an organized national colorectal cancer screening programme: Results from the first 2.6 million invitations in England. Int J Epidemiol, 40, 712-8.

Walsh JE, Terdiman JP (2003). Colorectal cancer screening: Scientific review. JAMA, 289, 1288-96. 
Kai-Chow Choi et al

Wong BC, Chan AO, Wong WM, et al (2006). Attitudes and knowledge of colorectal cancer and screening in Hong Kong: A population-based study. J Gastroenterol Hepatol, 21, 41-6.

World Health Organization 2014. Global health estimates 2014 summary table: DALY by cause, age and sex, 2000-2012, Geneva, World Health Organization.

World Health Organization. 2015. Screening for colorectal cancer [Online]. 